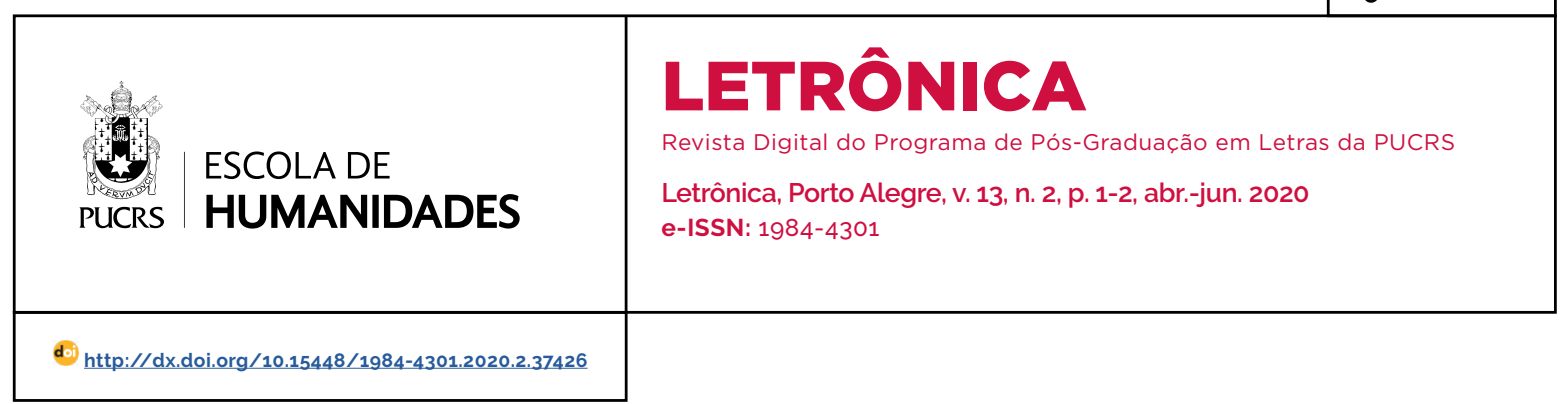

\title{
Corrêa, Sergio; Andreazza, Tiaraju; Maciel, Everton (org.). Política Prática. Macapá: Universidade Federal do Amapá, 2020.
}

\section{Baal Delupi ${ }^{1}$ \\ orcid.org/0000-0001-7697-3325 delupibaal@gmail.com}

Recebido em: 20 out. 2019 Aprovado em: 23 mar. 2020. Publicado em: 13 ago. 2020.

\section{(c) (i)}

Artigo está licenciado sob forma de uma licença Creative Commons Atribuição 4.0 Internacional.
Hace más de 40 años Deleuze planteó la necesidad de dejar de lado a los especialistas para dar paso a los creativos. El filósofo francés decía que las disciplinas no pueden estar aisladas, trabajando solas sin contacto con otros campos del conocimiento. Casi en el mismo momento, su compañero Guattari (2013) postuló que hay que salir de las "teorías generales" para atravesar, de modo rizomático, campos múltiples.

Politica práctica (2020) de la editorial Macapá-UNIFAP, cuenta con este espiritu, la interdisciplina: como bien se explica en la introducción, filosofía, política, religión, economía, educación y comunicación son algunas de las materias que se ponen en juego para el desarrollo de una "vocación para la práctica".

Este libro está estructurado por una introducción y catorce capítulos que atraviesan escuelas de pensamiento con la intensión de expandir la práctica filosófica. Muchos de los tópicos de estos escritos giran en torno a la reflexión y la acción en la contemporaneidad. ¿Cómo articular la teoría con la práctica? ¿Cómo pensar el entrecruzamiento de espacios académicos y acción política? Son algunas de las cuestiones que este libro intenta responder.

Práctica política invita a desmontar aquello obvio, eso "ya dado" que siempre es ideológico y que está 'ahí, como instalado y que pocos cuestionan. En el devenir de los escritos el lector podrá encontrar posiciones críticas, de denuncia y de resistencia (Duarte Silva).

Relecturas de Platón (Alencar) o de Foucault (Díaz de vivary Soler o Maciel Correa) sirven para pensar la ética y la política en nuestra actualidad. Discusiones sobre el Estado y los sistemas político-económicos aparecen como un debate en muchos de los trabajos (Brod; Lastra Cid; Maciel y Andreazza; Nascimiento).

Por otro lado, uno de los aportes de este libro es la vinculación y problematización de temáticas contemporáneas: asuntos referidos a la cultura (Schio), la religión (Nascimiento), el género (Sebastián, Guerrero, Álvarez Terán y Gaona), la educación (Rohling), la economía financiera (Ávila Peres), los partidos politicos (Saidani), la fake-news (Cocchieri) y las redes sociales (Brod) dan cuenta de un documento que piensa la práctica política no de manera aislada del resto de la sociedad, sino como una praxis que debe atender las preocupaciones del presente. 
Otra singularidad que presentan estos discursos es que los autores son de diversos países, configurado un libro que se escribe en distintos idiomas: portugués, francés e inglés. Esto, lejos de ser un dato anecdótico, muestra la intensión de los compiladores de crear un escrito de multiplicidades, entrecruzamientos y heterogeneidades culturales, políticas y académicas.

Un eje que atraviesa este libro es la preocupación por la desigualdad y la opresión que genera el sistema y/o gobiernos (dependiendo de los artículos) en los distintos lugares del mundo. Ya sea por una inequidad en la educación, la cultura o las cuestiones de género, este libro se conjura como una suerte de denuncia, una especie de franco tirador (Said, 1996). Invita a cuestionar y pensar posibles líneas de fuga del sistema capitalista que nos sumerge en condiciones marginales y precarias.

Estos escritos refieren al sistema capitalista actual que se configura de manera singular a partir de lo que se puede denominar como "discursos del odio". Es en este contexto mundial donde ciudadanos comunes y corrientes, y los más altos funcionarios de distintos países (Bolsonaro en Brasil, Macri en Argentina, Trump en EEUU, VOX en España, etc.) construyen, en sus producciones discursivas, sujetos que quedan estigmatizados y sumergidos a los márgenes. Es entonces que este libro intenta pensar formas de resistencia y de "contra información" (Deleuze, 2007) que permitan disputarle sentido a un sistema que tiene la virtud de reterritorializar (expropiando) todo lo que aparece como amenaza.

Otro aspecto relevante es la preocupación por la problemática comunicacional (Cocchieri; Brod). La cuestión de las redes sociales y las fake-news adquieren gran relevancia en todos los asuntos vinculados a la circulación del sentido, es decir, no solo hay que estar alertas en relación a cómo se informa, sino también a cómo circulan los mensajes hoy en día.

Como último eje temático, interesa señalar los trabajos sobre ética y subjetividad (Corrêa), cuestión fundamental para los tiempos que corren. Foucault parece ser el autor indicado para problematizar el estatuto de lo humano y lo animal.

En definitiva y como su nombre lo indica, este libro tiene una fuerte preocupación por la cuestión de la práctica política. ¿De qué manera puede pensarse la política hoy? Es quizá una de sus preguntas centrales. Lejos de mostrar un pesimismo brutal, los artículos esconden un importante vitalismo frente a lo que nos rodea. Es la cruda realidad la que esconde la verdadera posibilidad de acción, entendiendo que en un contexto político donde muchas cosas parecen difíciles de cambiar, todo se vuelve posible una vez más.

\section{Referencias}

DELEUZE, Gilles. Dos regímenes de locos, textos y entrevistas (1975-1995). Valencia: Pre-Textos, 2007.

GUATTARI, Félix. Lineas de fuga. Por otro mundo de posibles. Buenos Aires: Cactus, 2013.

SAID, Edward. Representaciones del intelectual. Buenos Aires: Paidós, 1996.

\section{Baal Delupi}

Profesor de Gramática III de la Facultad de Humanidades de la Universidad Nacional de la Pampa. Se desempeña en la ciudad de Córdoba, Argentina, como becario doctoral de semiótica por la Secretaría de Ciencia y Tecnología (SeCyT) de la Universidad Nacional de Córdoba (UNC), e integra el equipo de investigación Discurso Social. Lo visible y lo enunciable del Centro de Estudios Avanzados de la UNC.

\section{Dirección:}

Baal Delupi

Universidad Nacional de Córdoba

Av. Haya de la Torre $\mathrm{s} / \mathrm{n}$

Córdoba capital, Ar, Argentina. 